\title{
Cardiac rehabilitation: socially deprived patients are less likely to attend but patients ineligible for thrombolysis are less likely to be invited
}

\author{
M R Melville, C Packham, N Brown, C Weston, D Gray
}

\begin{abstract}
Objective-To identify factors associated with the uptake of cardiac rehabilitation following acute myocardial infarction.

Design-Retrospective analysis using multivariate logistic regression modelling.

Setting-Two large teaching hospitals in Nottingham.

Patients-Cohorts of patients admitted with acute myocardial infarction in 1992 and 1996.

Interventions-None.

Main outcome measures-Factors in multivariate analysis found to be associated with attendance at cardiac rehabilitation. Use of secondary prevention in those who were and were not invited and those who did and did not attend cardiac rehabilitation.

Results-58\% of all patients were offered cardiac rehabilitation. Attendance rates were $60 \%$ in 1992 and $74 \%$ in 1996. Invitations were more likely to be offered to younger patients, those who had received thrombolysis, and to patients admitted to one of the two Nottingham hospitals. Use of secondary prevention was only $48 \%$ in 1992 but this increased to $80 \%$ in 1996 . Patients not receiving secondary prevention were less likely to be invited to cardiac rehabilitation. Social deprivation was the only factor significantly associated with poor uptake of cardiac rehabilitation in both years. There was no difference in the use of secondary prevention between those who did and did not attend cardiac rehabilitation.

Conclusion-Those invited to attend a cardiac rehabilitation programme are likely to be in a good prognosis group, comprising those who are young and have received thrombolysis. Those at greatest risk, particularly patients from socially deprived areas, seem to be missing out on the potential benefits of cardiac rehabilitation. High risk patients should be specifically targeted to ensure that they are invited to, and encouraged to, attend a programme of cardiac rehabilitation. (Heart 1999;82:373-377)
\end{abstract}

Keywords: cardiac rehabilitation; acute myocardial infarction; thrombolysis

Following acute myocardial infarction, a comprehensive cardiac rehabilitation programme can reduce the risk of fatal acute myocardial infarction, sudden death, and death from all causes. ${ }^{12}$ For those individuals with high levels of anxiety or depression after acute myocardial infarction, there is some evidence to suggest a more rapid psychological recovery ${ }^{3-6}$ and quicker return to a normal quality of life, although this is disputed. ${ }^{8}$ Cardiac rehabilitation also provides an important opportunity to review the use of drugs relevant to secondary prevention, ${ }^{9}$ and to reinforce behaviour change, which may be achieved through the use of relevant educational principles. ${ }^{10}$

Despite these unequivocal benefits, not all patients receive an invitation to cardiac rehabilitation and this may be related to the hospital, the age and sex of the patient, and the type of consultant. ${ }^{11}$ Uptake by those invited may also be poor, the most common factors cited by patients being transport related difficulties, deteriorating clinical state, or improvements in general wellbeing before attending. ${ }^{12}{ }^{13}$ Pell and colleagues ${ }^{11}$ reviewed co-morbid factors (but not in-hospital treatment or events) and found social deprivation to be the most significant factor associated with poor uptake of cardiac rehabilitation; this association is important as these patients have a worse prognosis following myocardial infarction. ${ }^{14}$

We were interested in determining which clinical, secondary preventive, and social factors were associated with being invited to, and attending, a cardiac rehabilitation programme and whether deprivation was a significant factor relating to attendance and acceptance of cardiac rehabilitation.

\section{Methods}

PATIENTS

The Nottingham heart attack register (NHAR) records details of all patients admitted with a suspected heart attack to the two Nottingham hospitals. The methods of data collection have been described in depth elsewhere. ${ }^{15}$ We linked the details of all Nottingham district patients on the register who had been admitted with a definite or probable myocardial infarction to the data collected by the cardiac rehabilitation teams. Data were available for the whole of 1992 and the first six months of 1996.

The classification of diagnoses used by the NHAR is as follows: Definite myocardial infarction - a history suggestive of acute myocardial infarction, together with both a rise in serial cardiac enzymes to at least twice the upper limit of normal and the development of new $Q$ waves on serial electrocardiography; 
Probable myocardial infarction - a history suggestive of acute myocardial infarction, together with either a rise in serial cardiac enzymes to at least twice the upper limit of normal or the development of new $Q$ waves on serial electrocardiography.

Those patients who died before they could have attended cardiac rehabilitation were excluded from the analyses.

A number of clinical variables listed in table 1 were chosen to assess how relevant they were in influencing receipt of an invitation and the uptake of cardiac rehabilitation. Deprivation was measured using the Townsend score, ${ }^{16} \mathrm{cal}-$ culated on the enumeration district specified by the address of each patient at the time of the index admission. Distance (of the patient's home address from hospital) was calculated using "MapInfo" software. Diuretic on discharge was used as a surrogate marker for heart failure. Complicated myocardial infarction was defined as the need for any of the following: urgent treatment for a tachyarrhythmiaventricular or supraventricular; inotropic support; invasive cardiac monitoring; a pacemaker; or intravenous nitrate for heart failure or ongoing pain.

Having identified the key factors related to uptake of cardiac rehabilitation, a subsequent analysis was carried out to assess whether those patients not invited or not attending cardiac rehabilitation were less likely to be discharged from hospital with secondary prevention $(\beta$ blockers and angiotensin converting enzyme (ACE) inhibitors). The use of lipid lowering treatment was not recorded on the NHAR at this time.

STATISTICAL METHODOLOGY

Differences in receiving an invitation to, and attending, cardiac rehabilitation between se- lected characteristics were analysed using univariate logistic regression with categorical variables as appropriate. Variables in the univariate analysis with $\mathrm{p}<0.05$ were put into a multivariate logistic regression model and tested in a forwards stepwise method using the statistical package for the social sciences. ${ }^{17}$ Regression analysis was performed on the Townsend score before stepwise selection of the other variables. In multivariate analysis, $\mathrm{p}<0.05$ was considered significant.

\section{Results}

PATIENT POPULATION

In 1992, 617 patients sustained a definite or probable myocardial infarction and were eligible for cardiac rehabilitation; 357 (58\%) received an invitation of whom $214(60 \%)$ commenced the rehabilitation programme. In the first six months of 1996, 261 patients sustained a myocardial infarction; 151 (58\%) were invited to the rehabilitation programme, of whom $112(74 \%)$ attended. Demographic status and clinical events are shown in table 1.

Five of the patients in 1992 had missing ECG codes. Because of lack of postcode data, a Townsend score could not be assigned for 45 patients in 1992 and 12 patients in 1996. In 1992 complete data were available for the multiple logistic regression analysis to identify factors associated with receiving an invitation in $570(92 \%)$ cases, and for attending cardiac rehabilitation in $323(90 \%)$ cases. Corresponding figures for 1996 were 249 (95\%) and 131 $(87 \%)$.

Those variables significant in the univariate analysis for invitation to cardiac rehabilitation and uptake of cardiac rehabilitation for each of the cohorts are shown in table 2 .

Table 1 Attendance at cardiac rehabilitation: clinical and demographic variables for 1992 the dataset.

\begin{tabular}{|c|c|c|c|}
\hline \multirow[b]{2}{*}{ Variable } & & \multicolumn{2}{|l|}{ Total } \\
\hline & & $1992\left(n=617^{\star}\right)$ & $1996\left(n=261^{\star}\right)$ \\
\hline Age (years) & & $\begin{array}{l}\text { Mean } 65.07 \text { median } 68 \\
\quad(\text { SD } 11.44) \text { range } 28-93\end{array}$ & $\begin{array}{l}\text { Mean } 66.45 \text { median } 66 \\
\quad(\text { SD 12.11) range } 26-92\end{array}$ \\
\hline \multirow[t]{2}{*}{ Sex } & Male & 404 & 174 \\
\hline & Female & 213 & 87 \\
\hline \multirow[t]{4}{*}{ Outpatient appointment } & Given & 486 & 209 \\
\hline & Not given & 131 & 52 \\
\hline & Hopital A & 220 & 98 \\
\hline & Hospital B & 306 & 163 \\
\hline \multirow[t]{2}{*}{ Admitted to } & Other ward & 156 & 92 \\
\hline & CCU & 461 & 169 \\
\hline \multirow[t]{2}{*}{ Thrombolysis } & Not given & 277 & 141 \\
\hline & Given & 340 & 120 \\
\hline \multicolumn{2}{|l|}{ Length of stay } & $\begin{array}{l}\text { Mean } 7.5(\text { SD } 5.14) \\
\text { range } 1-62\end{array}$ & $\begin{array}{l}\text { Mean } 7.1(\mathrm{SD} 4.0) \\
\text { range } 1-39\end{array}$ \\
\hline \multirow[t]{2}{*}{ Cardiac history } & No & 455 & 205 \\
\hline & Yes & 162 & 56 \\
\hline \multirow[t]{2}{*}{ Complicated MI } & Uncomplicated & 460 & 185 \\
\hline & Complicated & 157 & 76 \\
\hline \multirow[t]{3}{*}{ Killip score } & 2 or 3 & 47 & 21 \\
\hline & 1 & 184 & 86 \\
\hline & 0 & 384 & 154 \\
\hline \multirow[t]{2}{*}{ Diagnosis } & Definite AMI & 321 & 111 \\
\hline & Probable AMI & 296 & 150 \\
\hline \multirow[t]{2}{*}{ Diuretic on discharge } & No diuretic & 417 & 187 \\
\hline & Diuretic & 200 & 74 \\
\hline Townsend score & & $\begin{array}{c}\text { Mean } 0.08(\mathrm{SD} 3.4) \\
\text { range }-5.8-+8.7\end{array}$ & $\begin{array}{l}\text { Mean } 0.15(\mathrm{SD} 3.4) \\
\quad \text { range }-5.7-+7.87\end{array}$ \\
\hline Distance from home $(\mathrm{km})$ & & $\begin{array}{l}\text { Mean } 6.2(\mathrm{SD} 3.6) \\
\text { range } 0-24\end{array}$ & $\begin{array}{l}\text { Mean } 6.4(\mathrm{SD} 4.1) \\
\text { range } 0.4-20.9\end{array}$ \\
\hline
\end{tabular}

*Except for Townsend score when $\mathrm{n}=572$ for 1992 and 249 for 1996 .

CCU, coronary care unit, AMI, acute myocardial infarction. 
Table 2 Factors significant in univariate logistic regression analysis for receiving an invitation to and attending cardiac rehabilitation for the 1992 and 1996 cohorts

\begin{tabular}{|c|c|c|c|c|}
\hline \multirow[b]{2}{*}{ Variable } & \multicolumn{2}{|l|}{1992} & \multicolumn{2}{|l|}{1996} \\
\hline & $\begin{array}{l}\text { Receiving } \\
\text { invitation to } \\
\text { CR }\end{array}$ & $\begin{array}{l}\text { Uptake of } \\
C R\end{array}$ & $\begin{array}{l}\text { Receiving } \\
\text { invitation to } \\
C R\end{array}$ & $\begin{array}{l}\text { Uptake of } \\
C R\end{array}$ \\
\hline Age & $\boldsymbol{}$ & $\boldsymbol{}$ & $\boldsymbol{}$ & \\
\hline Sex & レ & & レ & \\
\hline Outpatient appointment & & & $r$ & $\boldsymbol{}$ \\
\hline Admitted to (hospital) & $\boldsymbol{\nu}$ & $\boldsymbol{\nu}$ & $\boldsymbol{\nu}$ & \\
\hline Admitted to (ward) & $\boldsymbol{}$ & & & \\
\hline Thrombolysis & $\boldsymbol{v}$ & レ & $\boldsymbol{\nu}$ & レ \\
\hline Length of stay & $\boldsymbol{}$ & & & \\
\hline Cardiac history & 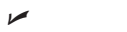 & & $\boldsymbol{r}$ & \\
\hline Complicated MI & & & & \\
\hline Killip score & $\boldsymbol{}$ & & & \\
\hline NHAR classification & $\boldsymbol{\nu}$ & & レ & $\boldsymbol{\nu}$ \\
\hline Diuretic on discharge & レ & & レ & \\
\hline Townsend score & 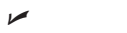 & 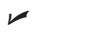 & & レ \\
\hline Distance from home & & & & \\
\hline
\end{tabular}

CR, cardiac rehabilitation; NHAR, Nottingham heart attack register.

MULTIVARIATE ANALYSIS

1992 cohort

Patient factors associated with receiving an invitation to cardiac rehabilitation were younger age $(\mathrm{p}=0.0013)$, male sex $(\mathrm{p}=0.008)$, and being discharged without diuretic drugs $(\mathrm{p}=0.02)$. Hospital factors associated with receiving an invitation were admission to hospital A ( $\mathrm{p}<0.0001)$, being admitted to the coronary care unit (CCU) $(\mathrm{p}=0.0012), \quad$ receiving thrombolysis $(\mathrm{p}=0.0001)$, short length of stay $(\mathrm{p}=0.029)$, and receiving an outpatient appointment $(\mathrm{p}<0.0001)$ (table 3$)$. Deprivation was not a significant factor.

Four factors were significantly and independently associated with commencing cardiac rehabilitation (table 3); three of these-being admitted to hospital $\mathrm{B}(\mathrm{p}=0.003)$, older age $(p=0.24)$, and a higher Townsend score (implying greater social deprivation, $\mathrm{p}=0.014)$-reduced the likelihood of attendance, and only one-receiving thrombolysis $(p=0.002)$-increased the likelihood of attendance.

\section{6 cohort}

In 1996 the patients who received an invitation were more likely to be younger $(p=0.0012)$, have been admitted to hospital A ( $\mathrm{p}=0.004)$, received thrombolysis ( $p=0.0014)$, and had a "definite" myocardial infarction $(\mathrm{p}=0.0025)$ (table 4).

Three factors were independently associated with uptake of cardiac rehabilitation, all of which reduced the likelihood of attendance. These were a higher Townsend score $(\mathrm{p}=0.015)$, a history of previous myocardial infarction or revascularisation $(p=0.0054)$, and not receiving an outpatient appointment $(\mathrm{p}=0.04)($ table 4$)$.

Table 3 Factors significant following multivariate logisitic regression analysis * of variables in 1992 associated with receiving an invitation to and uptake of cardiac rehabilitation

\begin{tabular}{|c|c|c|c|c|c|}
\hline \multirow[b]{2}{*}{ Variable } & & \multicolumn{2}{|c|}{$\begin{array}{l}1992 \text { receiving invitation to } C R \\
(n=570)\end{array}$} & \multicolumn{2}{|c|}{$\begin{array}{l}1992 \text { uptake of } C R \\
(n=323)\end{array}$} \\
\hline & & $O R$ & $(95 \% C I)$ & $O R$ & $(95 \% C I)$ \\
\hline Townsend score & & $0.96+$ & (0.90 to 1.02$)$ & $0.92 \dagger$ & (0.85 to 0.98$)$ \\
\hline Age & & $0.97 \ddagger$ & (0.95 to 0.99$)$ & $0.97 \ddagger$ & (0.95 to 0.99$)$ \\
\hline Sex & Male & 05 & 1.0 & & \\
\hline Admitted to & $\begin{array}{l}\text { Hospital A } \\
\text { Hospital B }\end{array}$ & 0.17 & $\begin{array}{l}1.0 \\
(0.10 \text { to } 0.27)\end{array}$ & 0.40 & $\begin{array}{l}1.0 \\
(0.25 \text { to } 0.66)\end{array}$ \\
\hline Admitted to & $\begin{array}{l}\text { Other ward } \\
\text { CCU }\end{array}$ & 2.27 & $\begin{array}{l}1.0 \\
(1.38 \text { to } 3.73)\end{array}$ & & \\
\hline Thrombolysis & $\begin{array}{l}\text { Not given } \\
\text { Given }\end{array}$ & 2.38 & $\begin{array}{l}1.0 \\
(1.52 \text { to } 3.72)\end{array}$ & 2.28 & $\begin{array}{l}1.0 \\
(1.35 \text { to } 3.87)\end{array}$ \\
\hline Length of stay & & 0.94 & (0.89 to 0.99$)$ & & \\
\hline Diuretic on discharge & $\begin{array}{l}\text { No diuretic } \\
\text { Diuretic }\end{array}$ & 0.76 & $\begin{array}{l}1.0 \\
(0.60 \text { to } 0.96)\end{array}$ & & \\
\hline Outpatient appointment & $\begin{array}{l}\text { Given } \\
\text { Not given }\end{array}$ & 0.31 & $\begin{array}{l}1.0 \\
(0.18 \text { to } 0.54)\end{array}$ & & \\
\hline
\end{tabular}

^Regression analysis performed on deprivation before stepwise selection of other variables; †per unit change in deprivation score; łper year; Sper day.

$\mathrm{OR}$, odds ratio; $\mathrm{CI}$, confidence interval.

Table 4 Factors significant following multivariate logisitic regression analysis ${ }^{\star}$ of variables in 1996 associated with receiving an invitation to and uptake of cardiac rehabilitation

\begin{tabular}{|c|c|c|c|c|c|}
\hline \multirow[b]{2}{*}{ Variable } & & \multicolumn{2}{|c|}{$\begin{array}{l}1996 \text { receiving invitation to } C R \\
(n=249)\end{array}$} & \multicolumn{2}{|c|}{$\begin{array}{l}1996 \text { uptake of } C R \\
(n=131)\end{array}$} \\
\hline & & $O R$ & $(95 \% C I)$ & $O R$ & $(95 \% C I)$ \\
\hline \multicolumn{2}{|l|}{ Townsend score } & $0.96+$ & (0.89 to 1.05$)$ & $0.85 \dagger$ & (0.85 to 0.98$)$ \\
\hline Age & & $0.96 \ddagger$ & (0.94 to 0.98$)$ & & \\
\hline \multirow{2}{*}{ Admitted to } & Hospital A & & & & \\
\hline & Hospital B & 0.41 & $(0.23$ to 0.75$)$ & & \\
\hline \multirow[t]{2}{*}{ Thrombolysis } & Not given & & 1.0 & & \\
\hline & Given & 2.55 & (1.44 to 4.54$)$ & & \\
\hline \multirow[t]{2}{*}{ Diagnosis } & Definite & & 1.0 & & \\
\hline & Probable & 0.41 & $(0.23$ to 0.73$)$ & & \\
\hline \multirow[t]{2}{*}{ Cardiac history } & No & & & & 1.0 \\
\hline & Yes & & & 0.24 & (0.09 to 0.65$)$ \\
\hline \multirow[t]{2}{*}{ Outpatient appointment } & Given & & & & \\
\hline & Not given & & & 0.30 & $(0.10$ to 0.92$)$ \\
\hline
\end{tabular}

* Regression analysis performed on deprivation before stepwise selection of other variables; tper unit change in deprivation score; ‡per year. 
SECONDARY PREVENTION

Use of aspirin was almost universal in both 1992 and 1996 cohorts. In 1992, only $48 \%$ of patients were discharged with a $\beta$ blocker or ACE inhibitor as additional secondary prevention. More of these were invited to cardiac rehabilitation than those who were not prescribed $\beta$ blocker or ACE inhibitor treatment (62\% compared to $54 \%$ ), although this did not achieve significance $(p=0.57)$. In 1996 use of additional secondary prevention had risen to $80 \%$ and patients invited to cardiac rehabilitation were significantly more likely to have been prescribed these drugs than those who were not invited $(p=0.007)$. There was no significant difference in the use of additional secondary prevention between those who did and did not attend $(1992, \mathrm{p}=0.26 ; 1996, \mathrm{p}=0.72)$.

\section{Discussion}

Cardiac rehabilitation has changed considerably over the past 20 years, from its exercise based origins to a more comprehensive approach aimed at reducing risk of subsequent cardiac events. Since the mid-1980s, this has been accompanied in the UK by more widespread availability of rehabilitation. ${ }^{18}{ }^{19}$ Invitation rates to rehabilitation programmes after infarction are infrequently reported, but they can range from $36 \%$ in a large cohort in Glasgow (with an attendance rate of $60 \%{ }^{11}$ ) to $100 \%$ for a coronary care cohort (with attendance by $40 \%^{20}$ ). In Nottingham, rates are at least as good as these- $58 \%$ of patients received an invitation and attendance was as high as $74 \%$. Uptake is not always so good-in a cohort of patients over 62 years old only $21 \%$ attended. ${ }^{13}$

Variables analysed in our study were prespecified, based on reported or potential associations with acceptance of cardiac rehabilitation. Some variables were not incorporated because of lack of reliability of the patient record (for example, whether specialist cardiological advice had been given during the admission), or because of difficulty in determining to what extent these impinged on a patient's lifestyle (for example, the impact of comorbid factors ${ }^{11}$ ).

\section{PATIENT FACTORS ASSOCIATED WITH RECEIVING} AN INVITATION

Increasing age was the only patient factor associated with an invitation to cardiac rehabilitation being withheld. Increasing age and female sex have been shown to be independently associated with not being invited to cardiac rehabilitation in an earlier study. ${ }^{11}$ Diuretic on discharge was significant in 1992 and, along with sex, the disappearance of these variables by 1996 may reflect a change in the hospital processes related to inviting patients to cardiac rehabilitation.

Deprivation was measured using the Townsend score which is based on census data for unemployment, car ownership, overcrowding, and home ownership. In multivariate analysis socially deprived patients were no less likely to be invited, supporting findings in pre- vious work by Pell and colleagues using the Carstairs score. ${ }^{11}$

HOSPITAL FACTORS ASSOCIATED WITH RECEIVING AN INVITATION

Possibly the most obvious means of identifying patients suitable for cardiac rehabilitation is to review those who have received thrombolysis, those admitted to the CCU, and those who in addition to a good history have ECG and enzyme changes.

The difference in significant variables from 1992 to 1996 might be thought to suggest that the process for identifying patients suitable for cardiac rehabilitation had changed. For instance, admission to CCU was a highly significant factor in 1992, but along with length of stay was not significant in 1996. Also, while in 1992 patients with a register diagnosis of "definite" acute myocardial infarction (who have cardiac enzyme and ECG evidence to support a clinical diagnosis) and "probable" acute myocardial infarction (whose clinical diagnosis is supported by only one of these) were equally likely to be invited, by 1996 the latter were less likely to be offered cardiac rehabilitation. Yet as register "definite" and "probable" myocardial infarctions both meet the criteria of the World Health Organisation for "definite myocardial infarction", ${ }^{21}$ this suggests that any change in the process has not resulted in identifying those at higher risk of future events.

Admission to hospital B significantly reduced the chance of being invited to cardiac rehabilitation, although this factor had improved by 1996 . This is likely to be a reflection of the fact that hospital B had many more admissions and a non-funded cardiac rehabilitation team compared to hospital A.

Perhaps the most important hospital factor associated with receiving an invitation to attend cardiac rehabilitation was whether or not patients had received thrombolysis. We have now shown for the first time that those patients who received thrombolysis were significantly more likely to receive an invitation, probably because patients in this group are the most easily identified and the diagnosis is most clear early after admission.

What may be of greater importance is that we have found that those patients who are less likely to be invited to rehabilitation are not only less likely to receive thrombolysis-increasing their risk of an adverse outcome $\mathrm{e}^{22-24}$ - but are also less likely to receive secondary prevention and the benefit this confers.

FACTORS ASSOCIATED WITH UPTAKE OF REHABILITATION

Some factors associated with poor uptake of cardiac rehabilitation in 1992 (increasing age, being admitted to hospital $\mathrm{B}$, and not receiving thrombolysis) were no longer significant by 1996. The significance of a previous cardiac history in 1996 reflects the fact that many of these patients had attended cardiac rehabilitation before, and did not feel it was necessary to attend again. The increased likelihood that uptake of cardiac rehabilitation was reduced in those who did not receive an outpatients' 
appointment means that these patients missed out on two opportunities for review, and this needs to be examined.

The only factor related to poor uptake of cardiac rehabilitation that remained significant in both cohorts was deprivation, as was found in previous work. ${ }^{11}$

One factor-distance from home to hospital - which we expected to be associated with uptake was not significant in any of the analyses.

\section{IMPLICATIONS}

We are missing opportunities to reduce risk post acute myocardial infarction.

First, those patients denied access to cardiac rehabilitation are less likely to have received the benefits of proved treatments. This includes a previously unrecognised goup of patientsthose who are thrombolysis ineligible - as well as those not prescribed $\beta$ blockers or ACE inhibitors. These treatments may have been withheld because of a clear contraindication. Even so, these patients ought not to be denied access to any reasonable alternative way of reducing the risk of a subsequent cardiac event. Cardiac rehabilitation would seem entirely appropriate for this group.

A multidisciplinary working party recently recommended that rehabilitation should be offered to all who are likely to benefit, and that risk stratification should be used as part of the process to identify high risk groups. ${ }^{25}$ In addition they produced draft audit standards ${ }^{26}$ for cardiac rehabilitation to which it may be prudent to add whether or not patients, following acute myocardial infarction, received thrombolysis.

Second, older patients may also miss out on postacute myocardial infarction rehabilitation. These patients too are at increased risk but there is no evidence to suggest that these patients do not benefit from cardiac rehabilitation.

Third, many patients living in deprived areas are failing to attend rehabilitation even when they are invited. It is important to establish why this is so and further work is in progress.

After an acute myocardial infarction, one important role of the caring professions is to reduce risk wherever possible. If the treatment and outcome of these groups are to be improved then greater efforts should be made to target these patients and ensure that they are invited to, and encouraged to attend, rehabilitation programmes in hospital; alternatively, provision should be made for rehabilitation in the community; or for self directed alternatives such as the Heart Manual.

We are grateful to the cardiac rehabilitation staff (Helen Marsh, David Purdue, Lynne Williams and Amanda Banks) at the Nottingham hospitals for the provision of data.
We acknowledge the support of the staff of the NHAR which has been supported by the Department of Health since its inception in 1973. We would like to thank Dr Jim Pearson of the department of public health medicine and epidemiology for additional statistical advice, and Natasha Huff of the department of geography, University of Nottingham, for additional help with the mapping.

1 Oldridge NB, Guyatt GH, Fischer ME, et al . Cardiac rehabilitation after myocardial infarction. Combined experience of randomized clinical trials. $\mathscr{F} A M A$ 1988;260:945-50.

2 O'Connor GT, Buring JE, Yusuf S, et al. An overview of randomized trials of rehabilitation with exercise after myocardial infarction. Circulation 1989;80:234-44.

3 Oldridge N, Streiner D, Hoffmann R, et al. Profile of mood states and cardiac rehabilitation after acute myocardial infarction. Med Sci Sports Exerc 1995;27:900-5.

4 Lewin B, Robertson IH, Cay EL, et al. Effects of self-help post myocardial infarction rehabilitation on psychological adjustment and use of health services. Lancet 1992;339: 1036-40.

5 Linden W, Stossel C, Maurice J. Psychosocial interventions for patients with coronary artery disease: a meta-analysis. Arch Intern Med 1996;156:745-52.

6 Denollet J, Brutsaert DL. Enhancing emotional well-being by comprehensive rehabilitation in patients with coronary heart disease. Eur Heart $\mathcal{7}$ 1995;16:1070-8.

7 Oldridge N, Guyatt G, Jones N, et al. Effects on quality of ife with comprehensive rehabilitation after acute myocardial infarction. Am f Cardiol 1991;67:1084-9.

8 Jones DA, West RR. Psychological rehabilitation after myocardial infarction: multicentre randomised controlled trial. BMF 1996;313:1517-21.

9 Bowker TJ, Clayton TC, Ingham J, et al. A British Cardiac Society survey of the potential for the secondary prevention of coronary disease: ASPIRE (action on secondary prevention through intervention to reduce events) principal results. Heart 1996;75:334-42.

10 Mullen PD, Mains DA, Velez R. A meta-analysis of controlled trials of cardiac patient education. Patient Education and Counseling 1992;19:143-62.

11 Pell J, Pell A, Morrison C, et al. Retrospective study of influence of deprivation on uptake of cardiac rehabilitation. BM7 1996;313:267-8.

12 Pell JP, Morrison CE. Factors associated with low attendance at cardiac rehabilitation. British fournal of Cardiology 1998;5:152-4.

13 Ades PA, Waldmann ML, McCann WJ, et al. Predictors of cardiac rehabilitation participation in older coronary patients. Arch Intern Med 1992;152:1033-5.

14 Smith GD, Bartley M, Blane D. The Black report on socioeconomic inequalities in health 10 years on. BMf 1990;301:373-7.

15 Gray D, Keating NA, Murdock J, et al. Impact of hospital thrombolysis policy on out-of-hospital response to suspected myocardial infarction. Lancet 1993;341:654-7.

16 Townsend P, Davidson N. The Black report. In: Inequalities in health: Penguin, 1988

17 Statistical package for social sciences reference guide. Chicago: SPSS Inc, 1990

18 Horgan J, Bethell $\mathrm{H}$, Carson $\mathrm{P}$, et al. Working party report on cardiac rehabilitation. Br Heart $\mathcal{f} 1992 ; 67: 412-18$.

19 Davidson C, Reval K, Chamberlain DA, et al. A report of a working group of the British Cardiac Society: cardiac rehaborking group of the British Cardiac Society: cardiac reha1995;73:201-2.

20 McGee HM, Horgan JH. Cardiac rehabilitation programmes: are women less likely to attend? $B M \mathcal{F}$ 1992;305:283-4.

21 World Health Organization. Proposal for the multinational monitoring of trends and determinants in cardiovascular disease (MONICA) project and protocol. Geneva: Cardiovascular Diseases Unit WHO, 1983.

22 Ozbek C, Heisel A, Krause M, et al. Comparison of mortality from acute myocardial infarction in patients receiving anistreplase with those not receiving thrombolysis. Am F Cardiol 1995;76:1103-7.

23 Wilcox RG, Olsson CG, Skene AM, et al. Trial of tissue plasminogen activator for mortality reduction in acute myocardial infarction: Anglo-Scandinavian study of early thrombolysis (ASSET). Lancet 1988;ii:525-30.

24 Behar S, Gottlieb S, Hod H, et al. The outcome of patients with acute myocardial infarction ineligible for thrombolytic
therapy: Israeli thrombolytic survey group. $\mathrm{Am} \mathcal{F}$ Med therapy: Israeli th

25 Thompson DR, Bowman GS, Kitson AL, et al. Cardiac rehabilitation in the United Kingdom: guidelines and audit standards. Heart 1996;75:89-93.

26 Thompson DR, Bowman GS, DeBono DP, et al, eds. Cardiac rehabilitation guidelines and audit standards. London: Royal College of Physicians, 1997. 